\title{
THE PROPOSED IMPLEMENTATION OF RFID BASED ATTENDANCE SYSTEM
}

\author{
Rizwan Qureshi \\ Department of Information Technology, Faculty of Computing and Information \\ Technology, King Abdul-Aziz University, Jeddah 80213, Saudi Arabia
}

\begin{abstract}
Recent trends in Information and Communication Technology (ICT) embrace several smartphone applications in a variety of educational and industrial domains in the last several years. This research focuses to solve one of the promising problems of an educational domain to take attendance smartly using the Radio Frequency Identification (RFID) system. Current attendance system in King Abdul-Aziz University (KAU) Saudi Arabia is partly solving the attendance problem. There are several problems in the existing attendance systems such as time-consuming, the chance of mistakes, truancy issues, no contact with parent/guardian and not efficient because of roll call as taking manual attendance. The proposed RFID based attendance system will provide robust, secure and automatic attendance. The proposed system will use modern technology and support to institutions and parents to deal with most of the problems of existing attendance systems. There are several other benefits of RFID based system such as web-based and mobile interfaces, daily absent report, an automatic SMS alert to parent/guardian, reduce administrative work, improve the ratio of attendance, economical and highly efficient. The case study method will be used as a research design. The proposed system is developed and tested in KAU Saudi Arabia. The proposed system will have both web and mobile interfaces. The web interface will need the Internet to access the proposed system and the mobile interface will use the Android platform for the testing scenarios. The user will access the system to generate customized reports to review the status of students for a particular course. It is anticipated that the proposed system will significantly improve students' monitoring mechanisms hence enabling both parents and teachers in making appropriate decisions.
\end{abstract}

\section{KEYWORDS}

Radio frequency identification, case study, smart attendance system, educational domain, Scrum methodology

\section{INTRODUCTION}

The radio frequency identification (RFID) systems are getting popularity from last several years due to several reasons such as economical, time saving, resource saving, reduced effort and easy to implement [1]. It is important to trace inventory for any ecommerce company because of opening new markets such as Amazon, EBay and Ali Baba. The RFID components are developed using state-of-the-art technology to create and read tags. The efficiency and accuracy of RFID systems are improved. Wal-Mart, General Electric, USA Department of Immigration, and USA Department of Defense organizations are already getting the benefits of RFID based systems [23]. A RFID tag is composed of an antenna, a wireless transducer and an encapsulating material [4]. 
The proposed research is conducted to implement the RFID technology in educational domain to solve the problems of manual attendance method. There is always a requirement for the instructors to mark attendance of their students in each lecture [1]. Majority of institutions all over the globe are still using the traditional method to take attendance. The instructors are calling the name of each student and marking present or absent in from of his/her id and name over a paper. There are several problems associated with this method to marks attendance such as students only know their shortage if instructors are willing to inform them before the examination, time and cost consuming, proxy attendance, insecure, inefficient and inaccurate [1]. King Abdul-Aziz University (KAU) of Saudi Arabia is one of largest universities in Saudi Arabia is using an electronic system named Odus Plus to take attendance of students from last several years but students' attendance is still taken manually on a paper from taking printout by faculty. This is because Odus Plus is a web based academic management system running on the main server of the KAU. An instructor wastes enormous amount of time in each lecture while connecting to the main server. After login, the instructors call the names of students in order to mark attendance in electronic system similar to manual attendance method. To avoid such cumbersome activities, a majority of instructors take print out of attendance sheets from electronic system and mark attendance of the students manually. There are several problems associated with both electronic and manual attendance methods such as time and cost consuming, prone of errors, involvement of human efforts, tedious and inefficient. This research aims to address the main limitations of existing methods of taking attendance in KAU by proposing a fully automated system using RFID technology. This is achieved by using a customized Scrum methodology by a group of final semester students.

The paper is arranged as follows. Section 2 covers the problem description. Section 3 describes the related work. Section 4 illustrates the proposed solution.

\section{Problem Statement}

The manual attendance system is still practiced in majority of the institutions all over the globe. There are several problems associated with manual attendance system such as time consuming, costly, error prone, difficult to retrieve, cumbersome to take in case of large strength, chance of loss and insecure [1]. King Abdul-Aziz University (KAU) Saudi Arabia introduces Odus Plus attendance management system from last few years to address the main limitations of manual attendance system. There are several problems reported by the faculty about the Odus Plus such as it consumes approximately ten to fifteen minutes of each lecture to connect the main server and calling the names of students to mark attendance similar to manual attendance system. The majority of faculty take print out of the students attendance, of their respective courses, to avoid connection problem and mark attendance through Odus Plus. The electronic system is not solving the problems of KAU to automate the attendance process and it is ultimately inheriting all the limitations of manual attendance system. The research question is narrated in this paper as follows.

- How to propose a RFID based automated attendance system to address the main limitations of Odus Plus?

\section{RELATED WORK}

Gatsheni et al. [1] developed a system to automate the attendance of the students using RFID technology. A tag is issued to each student at the time of his/her registration in the Central University of Technology. The university is currently marking attendance manually. The proposed system is tested only by taking attendance of five students using RFID to conclude the 
results. The proposed research does not cover the loopholes of RFID tag system. The proposed system needs further validation to test in a real time environment to check its effectiveness. An analysis, of barcode and RFID technologies, was provided in the industrial context [5]. The intent of the proposed research was to identify the commonalities and differences of both technologies. White et al. [5] conducted a case study in a warehouse to conclude the results where both barcoding and RFID technologies were already practiced. The parameters used to report the case study were quantity and type of mistakes associated due to the implementation of barcoding and RFID technologies. White et al. concluded that RFID technology performed better having less mistakes and possessed high performance as compared to the bar coding technology in an operational environment. The reliability of data was low in case of RFID based technology whereas it is high in case of barcoding technology. It is suggested to practitioners that by amalgamating barcode and RFID technologies could provide better results by eliminating the limitations of both technologies but it would be expensive and complex to implement.

Schapranow et al. [6] conduct a research to highlight one of the main limitations of RFID technology that is security. It is illustrated that the security breaches in RFID technology make it easy for hackers to attack the system. A number of attacks are reported using RFID technology such as man-in-the-middle, RFID cloning and spoofing and replay attacks. Controlled signal interferences and data encryption systems can control the vulnerability of RFID technology.

An information management system is developed to take attendance of the students in an academic institute [7]. The student attendance management is using the web interface to mark attendance to replace the paper based traditional style to record present and absent. The main benefits of the web based attendance management system is that the record of attendance is accessible to the top management of academic institution in the form of detailed, summary and exception reports. These reports can be shared to the parents and guardians to take corrective actions. The information system is developed using model view controller (MVC) architecture. Ajax technology is used to provide the front end interfaces and MySQL database is used to store the data. The main limitations of the attendance management system are time, cost, effort and resources consumptions. The proposed attendance management system is failed to address the problems of the paper based attendance method. It is recommended as a future work to address the main limitations of the paper based attendance marking method.

Srindhi and Ramil [8] conduct a research to address the main limitations of manual attendance marking method. A computerized system is developed by integrating RFID and biometric technology to take the attendance of the students, faculty and administrative staff. The proposed system has two versions that are web and mobile. A student is always needed to register at the time of admission in the institution. A RFID tag is issued with a distinctive code to each registered student and his/her figure prints are also recorded. All the classes are equipped with RFID readers and scanners and the campus is also equipped with the hotspots. The RFID reader will read the tag of each student and scanner will be used to match the figure prints to avoid the fake attendance. There are several advantages of the proposed web based attendance management system such as automation, detailed, summary and exception reports, time saving, less errors, alert status of the students to management, parents and guardians through emails and simple mail message (SMS). The mobile version helps the students about campus events, crowded area, campus locations using Google map and check the status of attendance in all classes to avoid fines and disciplinary notices. The proposed research addresses most of the problems of existing manual attendance taking method but it is costly to implement. The use of scanner to detect the figure prints of all students is time consuming at the beginning of each lecture especially if the class strength is thirty or above [8]. 
A system is developed to automate the registration, attendance, upload questions to question bank and administration work [9]. The automated system is developed using PHP and MySQL. The objective is to eliminate the manual systems and paper free environment. The electronic system enables the college to save time, cost, effort, resources. It will increase the productivity, efficiency and accuracy of registration and attendance processes. The research claims that it does solve the problem in hand without providing any factual results. The research needs to validate the proposed system using quantitative or qualitative techniques. The research is reported only by providing use case diagram and graphical user interfaces.

The research is conducted to replace the manual method of taking attendance by an automated student attendance management system [10]. A student management information system is proposed to develop as a web service. The main objective of the proposed research is to support component based development (CBD) and reduce deployment cost. The web service allows the development team members to become programming language and platform independent. The development team members need only business logic on the customer side instead of writing code for each specific customer. It is proposed that student attendance will be taken using quick response $(\mathrm{QR})$ code scanner to identify unique $\mathrm{QR}$ of students' identity card. The information of students' attendance will be accessible to the server. The server will use an application programming interface (API) to check the authenticity of data. The authentic information will be retrieved. The proposed web service attendance management system needs validation to conclude the results that it is better than the traditional manual attendance method and modern automated methods such as RFID, biometrics and bar code scanner.

Sajid et al. [11] propose a conceptual model to mark attendance automatically. The proposed conceptual model uses face recognition technology to mark attendance of each student. Each class room will be equipped with a camera to take pictures of all students from different angles. The proposed automate attendance system will use two databases i.e., temporal and permanent. The temporal database will store the pictures that are taken in each lecture. The pictures will be taken thrice during a lecture i.e., at the beginning, middle and by the end. Gabor Filters or Jets is a popular image analyses tool. The filtering software will analyze the facial features of each student from the group photos. The permanent database will contain the previously stored photos of all students at the time of registering them in an institution. The permanent database contains the mask information that is calculated by facial fiducial points of the students such as nose, lips and eyes. The input photo of each student will be matched with the previously stored photo of a student. The attendance of a student will be marked present if both photos are matched otherwise absent in case of mismatch. The proposed conceptual model is hard to implement, complex, expensive. The proposed model is inaccurate in case of female students wearing veils. The proposed research is a theoretical model and it needs to implement and test in a real scenario to conclude the results [11].

Near field communication (NFC) technology is used to implement an automated attendance management system [12]. NFC is a wireless short range technology but its frequency is high. The communication between NFC enabled devices will only occur if they are in contact or within a close range. The research is conducted to eliminate the limitations of manual attendance marking system. The proposed automated attendance system is composed of three main components i.e., NFC tag, NFC enabled mobile device and a web server. There are three ways to implement the proposed system. In first case, the instructor carries NFC enabled mobile in the class room. Each student is issued an id card with a built in NFC tag. ID card of each student needs physical contact to the instructor's mobile device to mark the attendance. In second case, the student caries a NFC enabled mobile device and NFC smart tag is attached to a poster paper that is displayed in each class room. The attendance is marked automatically as a student will touch his/her mobile device to the NFC tag based poster paper. The instructor and student both carry NFC enabled 
mobile devices. The attendance will be taken as a student will touch the mobile screen of an instructor. The attendance input is stored in the MySQL database over a web server for data manipulation. The NFC based proposed system is at its earlier stages

Table 1. The main limitations of related work.

\begin{tabular}{|l|l|}
\hline Title & Limitations \\
\hline $\begin{array}{l}\text { Automating a student class attendance register } \\
\text { using radio frequency identification in South } \\
\text { Africa [1] }\end{array}$ & $\begin{array}{l}\text { The proposed system requires further testing } \\
\text { in a real time environment to conclude } \\
\text { results. }\end{array}$ \\
\hline $\begin{array}{l}\text { A Comparison of Barcoding and RFID } \\
\text { Technologies in Practice [5] }\end{array}$ & $\begin{array}{l}\text { A hybrid solution, integrating RFID and bar } \\
\text { code, would be expensive and complex for } \\
\text { the institutions to implement. }\end{array}$ \\
\hline $\begin{array}{l}\text { A Web Enabled Secured System for } \\
\text { Attendance Monitoring and Real Time } \\
\text { Location Tracking Using Biometric and Radio } \\
\begin{array}{l}\text { Frequency Identification (RFID) Technology } \\
\text { [8] }\end{array}\end{array}$ & $\begin{array}{l}\text { RFID and bar code based system is a costly } \\
\text { and complex. }\end{array}$ \\
\hline $\begin{array}{l}\text { Web Service for Student Attendance } \\
\text { Management System [10] }\end{array}$ & $\begin{array}{l}\text { QR code scanner is required in each class } \\
\text { room to implement the proposed attendance } \\
\text { system. }\end{array}$ \\
\hline $\begin{array}{l}\text { A conceptual model for automated attendance } \\
\text { marking system using facial recognition [11] }\end{array}$ & $\begin{array}{l}\text { The proposed conceptual model does not } \\
\text { cater to mark attendance of the female } \\
\text { students wearing veils. }\end{array}$ \\
\hline $\begin{array}{l}\text { TouchIn: An NFC Supported Attendance } \\
\text { System in a University Environment [12] }\end{array}$ & $\begin{array}{l}\text { The proposed system needs further } \\
\text { validation in a real time scenario to check its } \\
\text { effectiveness, economics, practicality and } \\
\text { complexity. }\end{array}$ \\
\hline RFID Based Attendance System [13] & $\begin{array}{l}\text { A customized microcontroller based smart } \\
\text { attendance system is proposed is hard to } \\
\text { implement. }\end{array}$ \\
\hline
\end{tabular}

and it needs testing in a real time scenario to check its effectiveness, economics, practicality and complexity [12].

Lim et al. [13] describe the technical details about the implementation of RFID based smart attendance system. The objective is to replace the traditional manual attendance marking system. RFID technology is an economic solution to mark attendance automatically as compared to other solutions such as NFC, biometric and QR code scanners. Lim et al [13] propose a cheaper RFID based attendance system that is portable and it can be taken to the class room instead of fixing RFID scanners in each class room. It can store data in the microcontroller using electrical erasable programmable read only memory. The proposed smart attendance system is tested from different angles that are top, side, corner and bottom. The maximum range of card detection is five centimetres. The proposed smart attendance system needs to validate in a real time environment. The proposed RFID system is a customized solution and it is hard for an institution to develop and implement.

A smart attendance system is proposed using machine learning [14]. The main components of proposed smart attendance system are camera, face recognition algorithm and database. The camera is installed in each class room to take pictures. The research is conducted using histogram of oriented gradients to identify faces of individual students and match with the previously stored 
images. The student is marked absent if the face recognition does not match. The database contains several images of each student those are taken from different angles. Several advantages are claimed that the proposed will be economical, fast and error free. The proposed system is not tested in a real time scenario in any institution to infer the results. The proposed system is a customized solution and it needs supervised and unsupervised training to detect faces accurately.

Another attempt is made to propose a smart attendance system using real time face recognition [15]. The proposed smart attendance system using principle component analysis (PCA) and Haar cascade algorithm to accurately identify the faces in a real time environment. The proposed real time face recognition system can detect several faces to identify employees or students as they will enter in the company or a class room. The main advantage of the proposed system is that the employees or students do not need to perform any action or attention to mark the attendance. The proposed smart attendance system is based on machine learning and there is a need of training to accurately mark the attendance. The proposed real time face recognition system is tested and the accuracy of objects detection is sixty eight percentages. In order to implement the proposed system, the accuracy of objects detection needs to improve. The practicality, time and cost are major constraints to use machine learning based systems for attendance purpose. The proposed system works best if light is very clear and the results are inaccurate in case of dim light. The main limitations of related work are shown in Table 1.

\section{The Proposed Solution}

There are several solutions proposed to automate the attendance in the last few years to address the limitations of manual attendance system. These solutions are based on automation of attendance system using state of the art technologies such as RFID, NFC, QR scanner, microcontroller and machine learning [15]. After reviewing the existing solutions, this author has selected RFID technology to propose a SYSTEM because it is cheap and easy to implement.

The proposed system is a medium project because it is to be accomplished in eight months using a team of undergraduate students. The project is divided into two phases: requirements engineering in phase 1; and the proposed system is built, tested and reviewed in phase 2 . The first task of requirement engineering is to select a suitable methodology to develop the proposed system. Agile methodologies are practiced in software industry from last several years such as XP and Scrum [16]. Each of the agile methodology has its own pros and cons [17]. XP is extremely suitable for short projects with small teams due to its strong engineering practices but it lacks in management practices. Scrum is well known for small and medium projects due to its strong management practices but it is deficient in engineering practices. Therefore a customized Scrum methodology is used to develop the proposed system to achieve the benefits of both methodologies. Figure 1 shows the main phases of the proposed Lean-Scrum methodology.

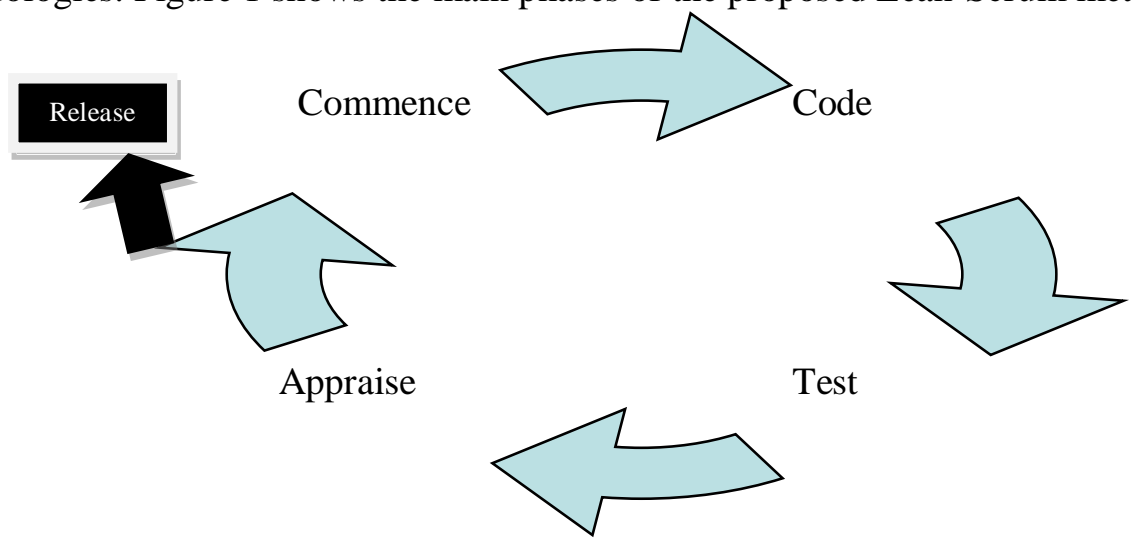

Figure 1. The main phases of customized Scrum methodology 
International Journal of Software Engineering \& Applications (IJSEA), Vol.11, No.3, May 2020

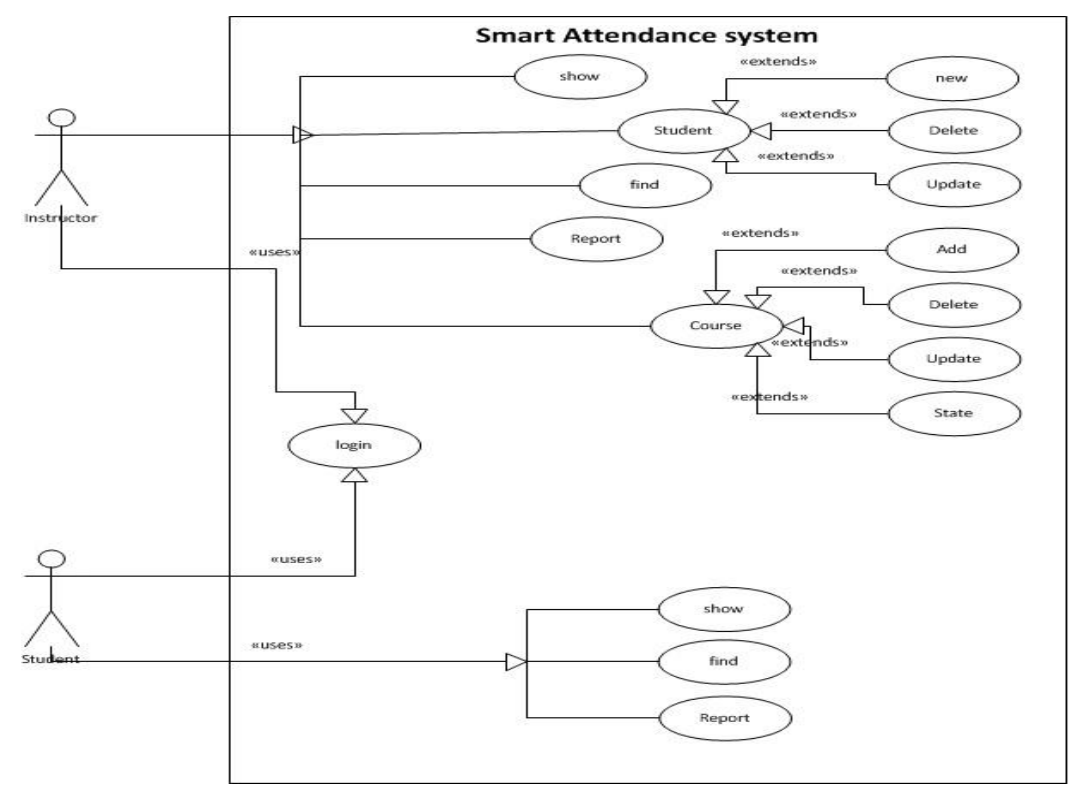

Figure 2. The use case diagram of proposed system

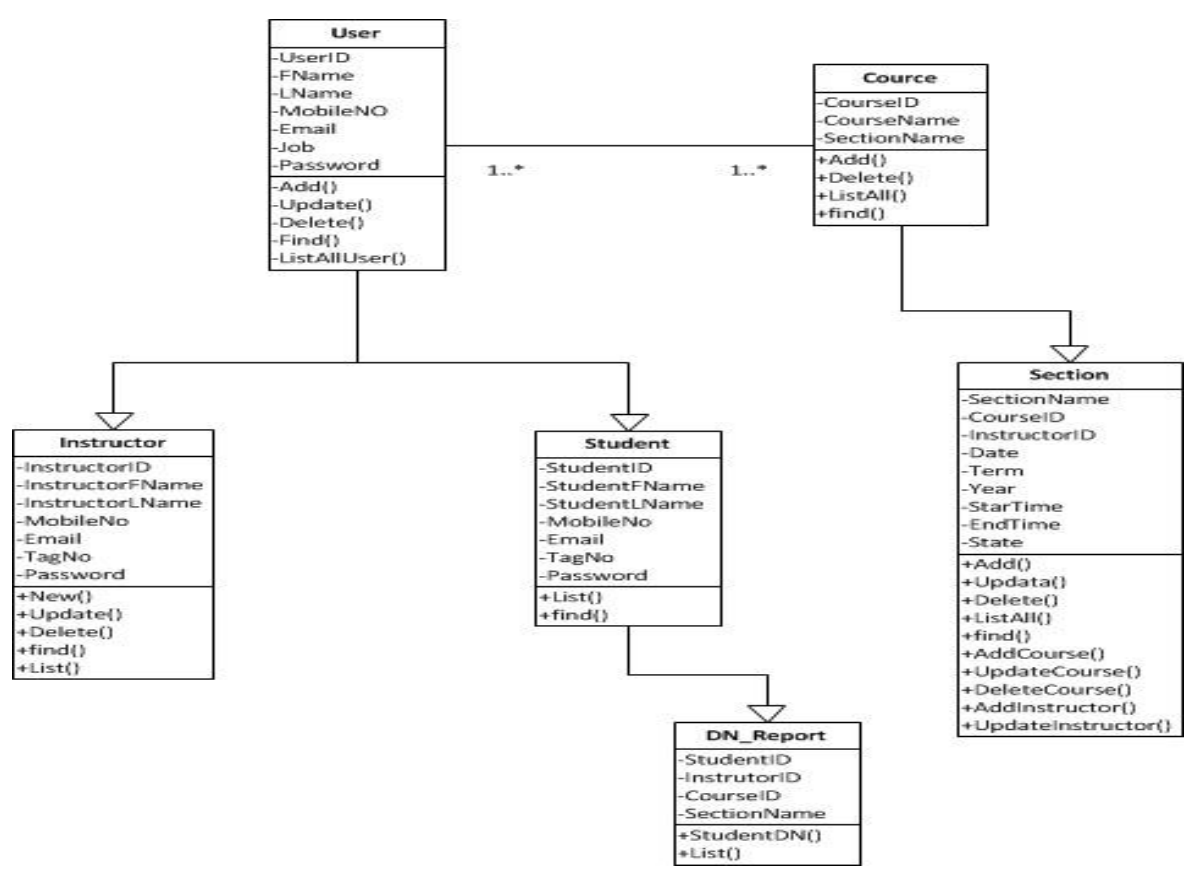

Figure 3. The class diagram of the proposed system

The main phases of customized Scrum model are Commence, Code, Test and Appraise.

\subsection{Commence Phase}

The project initiation activities are accomplished during the commence phase such as scope planning, verification and deliverables. The main objective is to identify needs, categorizing and 


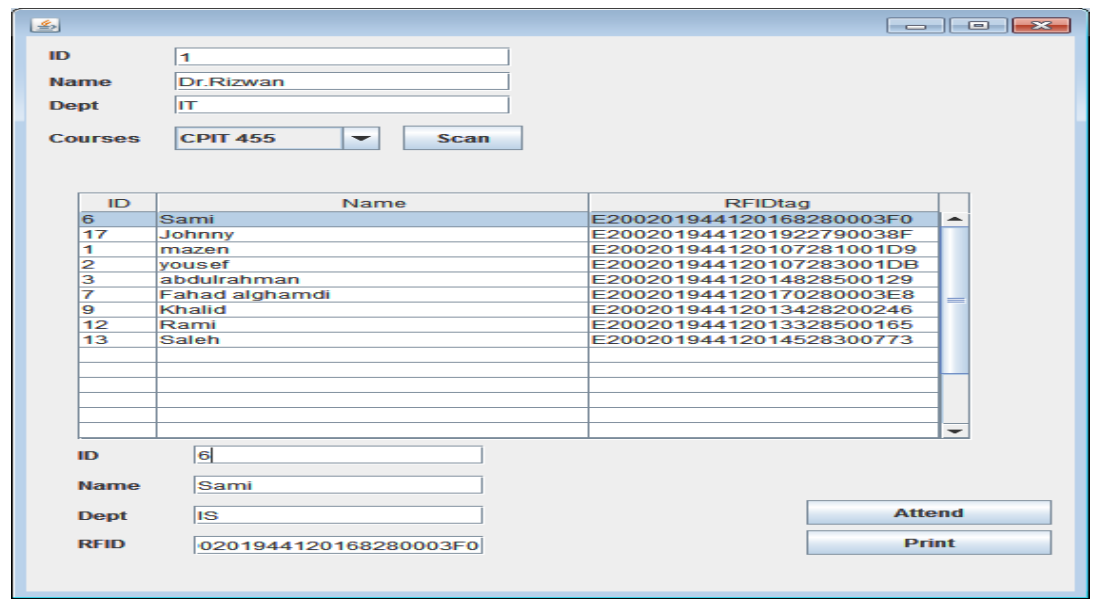

Figure 4. The web interface of proposed system

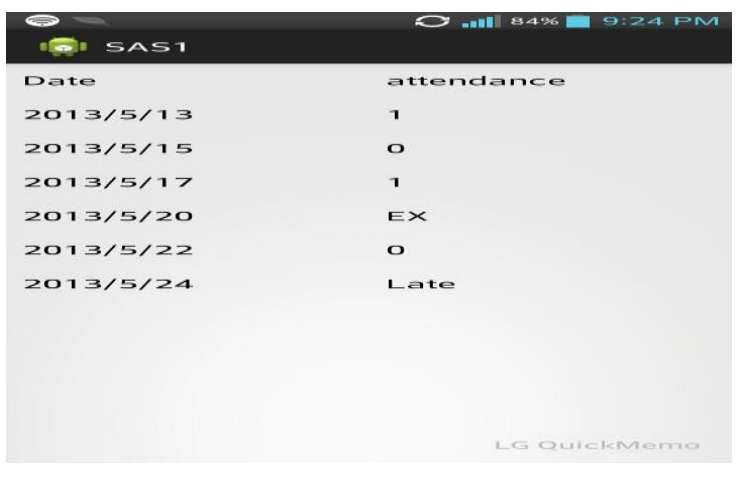

Figure 5. The mobile interface of proposed system

feasibility assessments of the project. The feasibility assessments include estimations of cost, schedule, effort, team size and software size. Financial analysis is performed to calculate net present value (NPV), return on investment (ROI) and payback analysis of the proposed RFID smart attendance system. The project manager, coordinator and development team roles are defined to implement the proposed smart attendance system. The project manager communicates to the users to collect user stories. The main users of the proposed system are students, instructors and management. The project manager provides a project backlog to the coordinator and development team. The project backlog is composed of a prioritized list of user stories. The main functional user stories of the proposed system are automatic attendance of the KAU students' using RFID and the instructors and management can access the database to search and generate required reports using web and mobile interfaces. The main tools require to develop the proposed system are RFID reader, NetBeans, Eclipse, Visual Studio.Net and MySQL. The Coordinator and team conduct a sprint meeting to decide the sprint backlog. The sprint backlog contains the number of stories completed in a release. Use case and class diagram is designed using a StarUML modeling tool. The interface specification and database design is prepared. The process is repeated at the commencement of each new release till project backlog is completed. The use case and class diagrams are shown in figures 2 and 3. The screen shots of the web and mobile versions of the proposed attendance system are provided in figures 4 and 5 . 


\subsection{Code Phase}

Pair programming, test driven development (TDD), refactoring and Kanban practices are used during the coding phase of the customized Scrum model. Test classes are written before writing

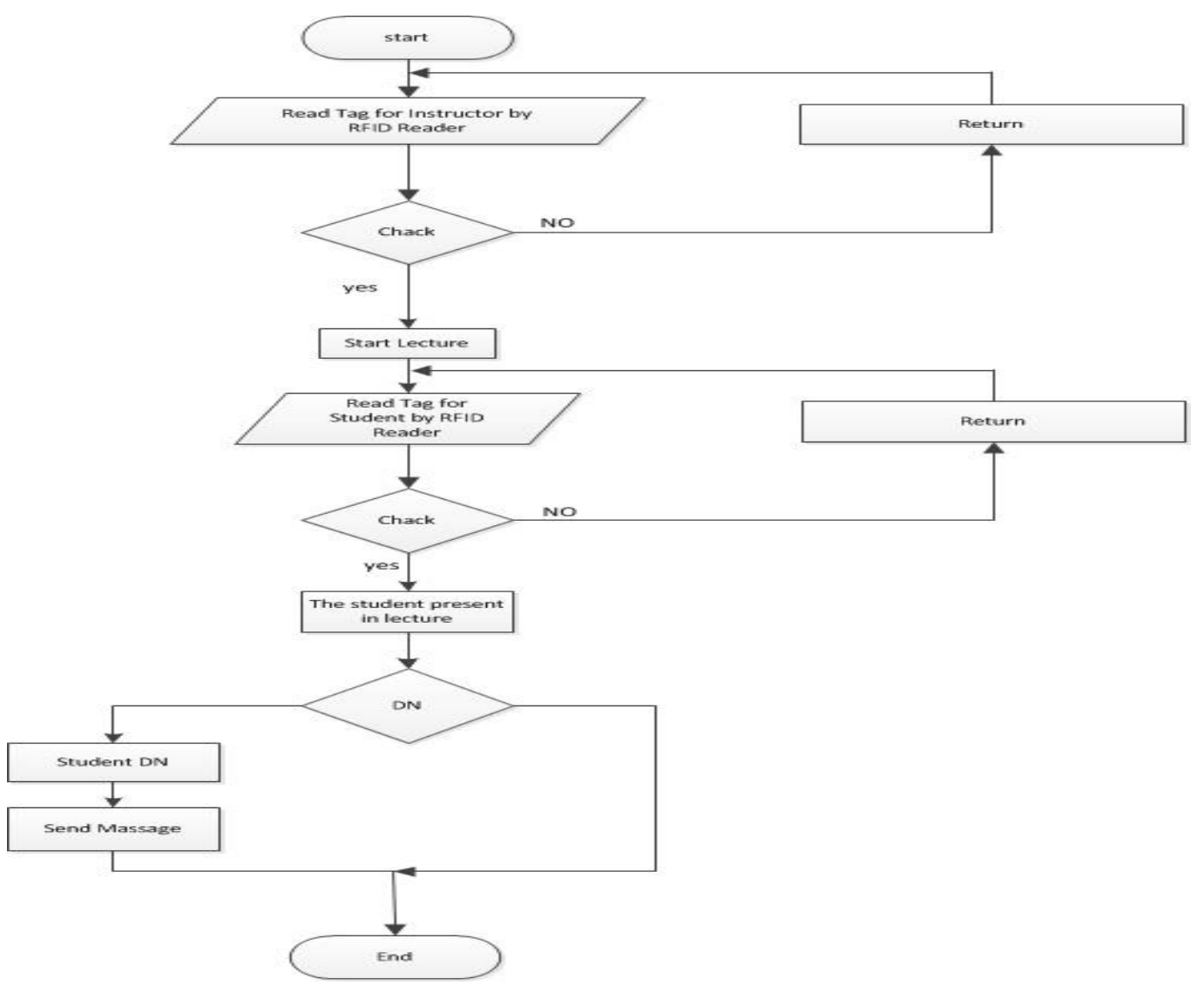

Figure 6. The flowchart diagram of the proposed system

the code. Two programmers work on one machine as per the pair programming practice [16]. One member writes the test classes and second member writes the code. Refactoring enables the team to improve the design or code at any stage during the development of the smart attendance system. Jira project management tool is used to allocate the user stories to the development team using Kanban practice. Kanban practice is taken from Lean methodology to keep work in progress under control. The sprint is integrated into a versioning system as it is completed. The coordinator facilitates the team during the coding phase. The designer team works closely with the development team to collaborate, deliver, reflect and improve. The flowchart diagram is shown in figure 6.

\subsection{Test Phase}

The team member, who has written the test classes, is responsible to test the code not the owner of code. The automated tools are used to test the code to ensure built-in integrity. JUnit is used for unit testing. FitNesse tool is used for integration and system testing. The project manager owner is invited for acceptance testing. GitHub is used as a version management system. The sprint is integrated into version management system. The configuration manager performs integration and system testing again. The sprint is labelled to ship if it is cleared from the integration and system testing. 


\subsection{Appraise Phase}

The project manager, coordinator and team are invited for a sprint review meeting before sprint is shipped to the customer. The main objective is to uncover errors in the function, logic or implementation. The project manager makes sure that sprint is covering the desired functionalities as per the selected user stories of the sprint backlog. The sprint is shipped to the customer if it is approved during the sprint review session. The project manager calls the sprint retrospective meeting before starting the activities of next sprint cycle. It will help the team to implement software process improvement and uncover mistakes in the overall activities of the customized Scrum methodology. The sprint retrospective aids in extruding extra activities, processes and resources.

\section{Conclusions}

The faculty of KAU Saudi Arabia is suffering due to the uprising problems of the current Odus Plus attendance system such as significant amount of time is wasted during the lecture while connecting to the server, roll call similar to the manual attendance system, error prone, proxy attendance and inefficient. An attempt is made to develop an automated attendance management system using RFID technology to address the limitations of Odus Plus system. The RFID based attendance system has two versions as per the requirements of the customer i.e., web and mobile versions. A customized Scrum methodology is used to develop the proposed system. The RFID system is successfully developed and tested by taking attendance in one of the class rooms in KAU. The results of the proposed RFID attendance system are found satisfactory that it addresses the main limitations of Odus Plus such as time saving, automated attendance, reduced the chances of proxy, accurate and efficient and warrants the proposal of the proposed system. The main limitation of the proposed system is that it requires a cost to install the RFID reader hardware in all class rooms and provide RFID tags to all students of KAU. There is also a recurring cost to maintain the proposed system. The future work is to implement the smart RFID system to mark the attendance of KAU administration.

\section{ACKNOWLEDGEMENT}

The author would like to thank KAU Jeddah Saudi Arabia for the technical and financial assistance.

\section{REFERENCES}

[1] Gatsheni, B.N., Kuriakose, R.B., Aghdasi, F., (2007) "Automating a student class attendance register using radio frequency identification in South Africa”, IEEE Int. Conf. Mechatronics, Japan, pp1-5.

[2] RFID4U, Basics-RFID Regulations, Available: https://rfid4u.com/rfid-basics-resources/basics-rfidregulations/, Accessed Date: 23 April 2020.

[3] Finkenzeller, K. (2010) RFID Handbook, John Wiley \& Sons Publisher.

[4] Texas Instruments, RF37S114 Tag-it TM HF-I Type 5 NFC, ISO/IEC 15693 Transponder, $4 \mathrm{~mm} \times 4$ mm, Available: https://www.ti.com/lit/ds/scbs907/scbs907.pdf, Accessed Date: 23 April 2020.

[5] White, GRT., Gardiner, G., Prabhakar G. \& Razak A., (2007) “A comparison of barcoding and RFID technologies in practice", J Info, Info Tech, and Orgs, Vol. 2, pp119-132. 
[6] Schapranow, M-P., Mueller, J., Zeier, A. \& Plattner H., (2011) "Security aspects in vulnerable RFIDaided supply chains", 5th European Workshop RFID Sys and Tech, Bremen, Germany, pp1-4.

[7] Jacksi, K., Ibrahim, F. \& Ali, S., (2015) "Student attendance management system", Sch J Eng and Tech, Vol. 6, pp49-53.

[8] Srinidhi, MB. \& Romil, R. (2015) “A web enabled secured system for attendance monitoring and real time location tracking using biometric and radio frequency identification (RFID) technology", Int Conf Comp Comm and Informatics, India, pp1-5.

[9] Sharma, PS., Shetty. RR., Yadkikar, GV. \& Kanade, D. (2016) “College automation system”, Int J Innov Res Sci \& Tech, Vol. 2, pp96-102.

[10] Anusha, PV., Atul, K., Kshama, PM. \& Menita, C., (2016) "Web service for student attendance management system”, Int J Adv Resh Sci and Engr, Vol. 5, pp319-323.

[11] Sajid, M., Hussain, R. \& Usman, M., (2014) “A conceptual model for automated attendance marking system using facial recognition”, Ninth Int Conf Digital Info Mang, Thailand, pp7-10.

[12] Ayu, MA. \& Ahmad, BI., (2014) "TouchIn: an NFC supported attendance system in a university environment”, Int J Inf Educ Tech, Vol. 4, pp448-453.

[13] Lim, TS., Sim, SC. \& Mansor, MM., (2009) "RFID based attendance system”, IEEE Symp Ind Elect and App, Malaysia, pp778-782.

[14] Madhu, S., Adapa, A., Vatsavaya, V. \& Padmini, P., (2019) "Face recognition based attendance system using machine learning”, Int J Mang, Tech and Engr, Vol. 9, pp2992-2995.

[15] Tharanga, JGR., Samarakoon, SMSC., Karunarathne, TAP., Liyanage, KLPM., Gamage MPAW. \& Perera, D., (2013) "Smart attendance using real time face recognition (SMART - FR)", SAITM Res Symp Engr Adv, Sri Lanka, pp41-44.

[16] Pressman, RS, (2015) Software Engineering, McGraw-Hill Publisher.

[17] Salo, O. \& Abrahamsson P., (2008) "Agile methods in European embedded software development organisations: a survey on the actual use and usefulness of Extreme Programming and Scrum", J IET SW, Vol. 2, pp58-64.

\section{AUTHOR}

Prof. Dr. Rizwan Qureshi received his Ph.D. degree in Computer Sciences from National College of Business Administration \& Economics, Pakistan 2009. He is currently working as a Professor in the Department of IT, King Abdulaziz University, Jeddah, Saudi Arabia. This author is the best researcher awardees from the Department of Information Technology, King Abdulaziz University in 2013 and 2016.

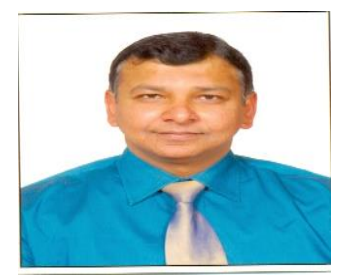

